\title{
Una competencia de pesos pesados por el dominio del mundo
}

\author{
Guillermo N. Murray-Tortarolo y Fabiola Murguía-Flores
}

\begin{abstract}
Resumen
Los seres humanos somos la especie dominante de nuestro planeta por donde se lo vea. Hemos cambiado los flujos de materia e información, entendido nuestro universo a profundidad y hasta modificado la esencia de la vida, los genes. Pero bajo un indicador ecológico, la dominancia, determinada por la masa de una especie, no necesariamente resultamos como los grandes campeones. En este artículo comparamos la biomasa de los seres humanos contra la de las plantas, los microorganismos y nuestro animal domesticado favorito, las vacas, a través de tres rondas de lucha de pesos pesados. Gracias a los cálculos más recientes, la tecnología satelital y las supercomputadoras, podemos darnos cuenta de que no ganamos ninguno de los tres asaltos, pues la biomasa de nuestros compañeros de planeta es mucho mayor a la nuestra. Acompañamos, entonces, en esta pelea de los gorditos, para descubrir un mundo dominado por todos, menos nosotros.
\end{abstract}

Palabras clave: biomasa global, dominancia ecológica, biosfera, biología cuantitativa.

\section{A HEAVYWEIGHT COMPETITION FOR WORLD DOMINATION}

\begin{abstract}
We humans are the dominating species of our planet. We have largely modified the matter and information fluxes of our planet, we have a deep understanding of our universe, and we even altered the very essence of life, genes. However, under one key ecological indicator, dominance — determined by the biomass of a species-, we may not be the sole rulers. In this article, we compared the biomass of human beings against plants, microorganisms and our favorite domesticated animal, cows, through three heavy-weight box rounds. Thanks to the most recent calculations, satellite technology, and supercomputers, we will show how we easily lose all three rounds, and how the biomass of our planetary neighbors is much bigger than ours. Join us, in this chubby box championship, to discover a world ruled by everyone, but us.
\end{abstract}

Keywords: global biomass, ecological dominance, biosphere, quantitative biology.

Recepción: 17/06/2020. Aprobación: 21/10/2020. Dol: http://doi.org/10.22201/cuaieed.16076079e.2020.21.6.15 


\section{Guillermo N. Murray-Tortarolo}

gmurray@iies.unam.mx orcid.org/0000-0002-5620-6070

Es Investigador Asociado "C" en el Instituto de Investigaciones en Ecosistemas y Sustentabilidad de la Universidad Nacional Autónoma de México (UNAM). Su tema principal de trabajo es la investigación ecológica a distintas escalas espacio-temporales. Le interesa entender los impactos del cambio y la variación climática sobre distintos procesos ecológicos y agronómicos de México y el mundo.

También tiene un profundo interés y pasión por la divulgación de la ciencia, y por la enseñanza de la misma.

\section{Fabiola Murguía-Flores}

fmurguia84@gmail.com

orcid.org/0000-0002-0582-6771

Es investigadora posdoctoral en el Instituto de Investigaciones en Ecosistemas y Sustentabilidad de la unam. Su línea de investigación es el consumo de metano por las bacterias del suelo a nivel global, pero le gustan todos los temas relacionados con los ciclos biogeoquímicos en los suelos. Es además fanática de la divulgación y la enseñanza de la ciencia a todos niveles. 


\section{Introducción}

Los seres humanos hemos modificado nuestro planeta como ninguna otra especie. Hemos alterado de manera radical los flujos de energía, materia e información, modificando el clima de la Tierra, la productividad de ciertas especies y hasta la misma esencia de la vida: los genes. Por donde lo veamos, somos seres superiores en nuestro mundo, los grandes amos y señores de la vida en la Tierra... ¿Cierto?

Posiblemente no. Tomemos el ejemplo de la dominancia ecológica para explicarlo. Una de las labores que más les gusta a los ecólogos es determinar la composición y estructura de las comunidades vegetales. Para ello, utilizan distintos índices, entre ellos el famoso índice de dominancia, que usa parámetros como la frecuencia, la abundancia y, en particular, la biomasa de las especies, para con ello determinar su "peso" en un ecosistema. La biomasa es, literalmente, el peso (la masa) que tiene una especie viva, y funciona como un buen indicador de su éxito ecológico (si tienes mucha masa, jdebe ser porque te va muy bien!).

Entonces, basándonos en este simple indicador, ¿somos los más abundantes en el planeta? ¿Es acaso la biomasa de los seres humanos mayor que la de otros organismos vivos, y somos los ganadores en el campeonato de pesos ecológico? En este artículo te lo platicamos. Como un campeonato de box, a lo largo de tres rondas pondremos a pelear la "gordura" de los humanos contra la de otros organismos y, te adelantamos, no ganamos ni una sola vez.

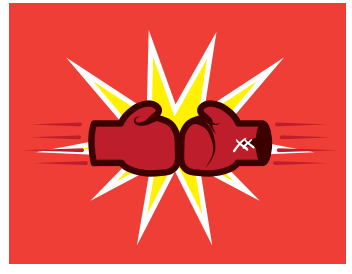

\section{Round 1: humanos vs. plantas}

Ronda uno. En la esquina izquierda tenemos a nuestros favoritos, llenos de sangre y huesos, los seres humanos. En la esquina derecha, a las duras, cafés, verdes e inmóviles, las plantas.

En primer lugar, revisemos la cantidad de individuos de la que estamos hablando y, así, hagamos un cálculo de su biomasa. De acuerdo con los últimos datos que revisamos (junio 2020), en este momento hay 7,790,202,015 personas en el mundo y para cuando leas esta nota seguro se habrá incrementado en algunos cuantos millones. Si el promedio de nuestro peso es de 70 kg, significa que los seres humanos tenemos una biomasa de 545 millones de toneladas. Esto lo sabemos gracias a los impecables récords de natalidad y mortalidad que lleva cada país.

No obstante, este no es el caso para los árboles... No hay ninguna nación que se haya dedicado a contar cada uno de ellos y tomar nota de cómo cambian sus poblaciones. Por suerte, en la era moderna contamos con satélites de resolución espectacular. Gracias a ello Tomas Crowther y colaboradores, en un artículo publicado en la revista Nature en 2015, estimaron que existen 3.04 
"Una competencia de pesos pesados por el dominio del mundo" Guillermo N. Murray-Tortarolo y Fabiola Murguía-Flores Vol. 21, Núm. 6, noviembre-diciembre 2020 Revista Digital Universitaria

billones de árboles, algo así como 422 por cada persona. De hecho, encontraron que, gracias a las plantaciones humanas, existen más árboles en la actualidad que hace 35 años. Siguiendo con sus estimados, Yinon Bar-On y colaboradores, calcularon la biomasa vegetal, en un artículo publicado en la revista Proceedings of the National Academy of Sciences, en 2018, y obtuvieron un valor de 4.5 billones de toneladas. En otras palabras, las plantas tienen algo así como 7500 veces más biomasa que la de los seres humanos. ¡Ups! No ganamos ni por poquito.

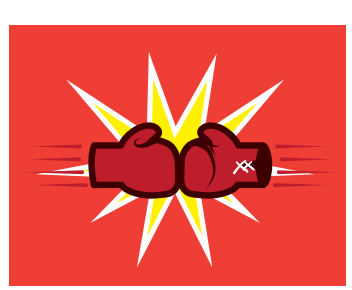

\section{Round 2: humanos vs. microorganismos}

Bueno, la ronda anterior era algo predecible. Los árboles son demasiado grandes, demasiado pesados y están por todos lados. Seguro que entonces le podemos ganar a los más diminutos, a los invisibles microorganismos. Comienza así nuestro segundo round. Nuevamente, en la esquina izquierda tenemos a los monos vestidos, que se enfrentan a nuestro nuevo retador, los minúsculos, microscópicos y más viejos habitantes del mundo: los microorganismos (ojo, el coronavirus se quedó afuera, por prevención a nuestra salud).

En la esquina de los pequeñines se encuentran todos los que miden menos de 5 micras, ¿sabes cuánto es eso? Una micra es la millonésima parte de un metro, así que somos como alrededor de 1.7 millones de veces más grandes que estos organismos. Sin embargo, en este caso el tamaño no es lo que importa si no la abundancia. Dentro de la categoría de microorganismos aquí agrupamos a las arqueas y las bacterias. ${ }^{1}$ Estos organismos fueron las primeras formas de vida en aparecer en nuestro planeta, por lo que tienen una alta capacidad de adaptación a casi cualquier ambiente. En la actualidad existen microorganismos en cada rincón de nuestro planeta, pueden habitar desde profundas fosas marinas, aguas sulfurosas volcánicas, estómagos de animales, hasta la masilla de nuestros dientes. De acuerdo con un estimado reciente (2019) de Hans-Curt Fleming y Stefan Wuerts, publicado en la revista Nature, hay aproximadamente $10^{30}$ bacterias y arqueas en todo el planeta. Este es un número muy grande, es un nonillón, o un 1 seguido de 30 ceros, de bichos; algo así como que el doble de microorganismos en la Tierra sería el mismo número de estrellas en la vía láctea. Tan sólo en una pizca de suelo puede haber hasta 40 millones de células bacterianas y hasta un millón en una gota de agua.

1 En su artículo, Fleming hace un estimado de la biomasa de los microorganismos que pertenecen a las bacterias y arqueas, que tienen un tamaño entre 0.5 y $5 \mu \mathrm{m}$. Existen otros seres microscópicos unicelulares, que pertenecen a los eucariontes, pero que son de mayor tamaño, por lo cual no se incluyen en este cálculo.
¿Por qué son tan abundantes? Por dos razones: tienen una alta capacidad adaptativa y su ciclo de vida es corto en comparación con los humanos, así que están por todos lados y se reproducen muy rápido. Su capacidad de adaptación es extraordinaria, ya que ningún otro ser vivo en nuestro planeta se atreve a vivir en los barrios donde éstas se la pasan de maravilla. Un ejemplo de estos ambientes son los géiseres y los cráteres de volcanes activos, lugares superinhóspitos e inhabitables por cualquier mortal, ¿cierto? Pues no es así. Existe un amigo llamado Pyrococcus furiosus y como ya lo imaginas por su 
"Una competencia de pesos pesados por el dominio del mundo" Guillermo N. Murray-Tortarolo y Fabiola Murguía-Flores

nombre, esta arquea pueden vivir en ambientes extremadamente calientes, de hecho su temperatura ideal es arriba de los $80^{\circ} \mathrm{C}$ (itemperatura que mataría a cualquier humano!). Otro ambiente muy extremo es el Mar Muerto, en el cual la salinidad es tan alta que si te echas un trago de esa agua te deshidratarías hasta la muerte. Sin embargo, las bacterias del género Halobacterium son más que felices ahí, pues sus adaptaciones les permiten vivir sin problemas en este ambiente salino. También están los microorganismos que soportan muchísima radiación como Thermococcus gammatolerans; los que viven en lo más profundo del mar, donde la presión es muy grande (como para aplastar a un humano y su auto), como Shewanella y Moritellaque se han encontrado a 11,000 metros bajo el mar; también los hay que viven en lo más profundo del suelo, como Bacillus infernus que puede vivir hasta a 2,700 metros bajo la superficie. Así que estos amigos habitan cada rincón y cada nicho de la Tierra.

Gracias a su enorme abundancia y capacidad para vivir en casi todos los ambientes terrestres, las bacterias y las arqueas representan alrededor de16\% de toda la biomasa del planeta. Traducido a toneladas, es algo así como 0.7 billones, o mil veces la materia de todos los seres humanos; por lo que nuestros pequeños amigos le ganan por mucho al Homo sapiens en cuanto a biomasa (iy en su capacidad de vivir en todos lados!).

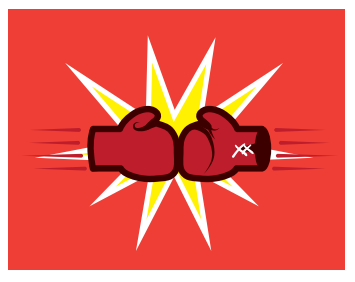

\section{Round 3: vs. el resto de los animales}

¡Que horror! Ni a los grandes, ni a los chicos les ganamos. Pero seguramente es porque son muy distintos a nosotros. Seguro ganaremos si nos enfrentamos a alguien más parecido: nuestros primos móviles, el resto de los animales. Casi exhaustos, pero aquí vamos por última vez, la pelea final: humanos contra el resto de los animales.

A lo mejor en este punto ya te habrás dado cuenta de que hasta ahora no había sido una pelea justa. Estábamos enfrentando a los seres humanos - una sola especie-, contra los miembros de otros reinos (plantas, y bacterias y arqueas, respectivamente), así que claramente hay un poco de trampa. No hagamos lo mismo para los animales, porque de seguro si nos enfrentamos a una única especie, entonces, sí podríamos ganar. Para el caso de los animales, pongamos el terreno un poco más justo, pongamos a "pelear" a los hombres contra su rumiante favorito: las vacas.

Primero, revisemos el número de habitantes vacunos en nuestro planeta. De acuerdo con el último estimado de la Organización de las Naciones Unidas para la Alimentación y la Agricultura (mejor conocida como FAO por sus siglas en inglés), para el 2018 —el más reciente estimado_ había 1,489,744,504 vacas en todo el mundo. ¡Esto es equivalente a una vaca por cada cinco personas! Y el número sigue creciendo y creciendo, por la incesante demanda por carne y leche en todas partes. Ahora bien, una vaca promedio pesa unos 500 kilos que, 
multiplicado por el número de vacas, nos da una biomasa de... j744 millones de toneladas o un 36\% más que la de todos los humanos que habitamos este planeta! Así que perdimos este asalto también. ¡Que desilusión! i Y nosotros pensando que dominábamos este planeta!

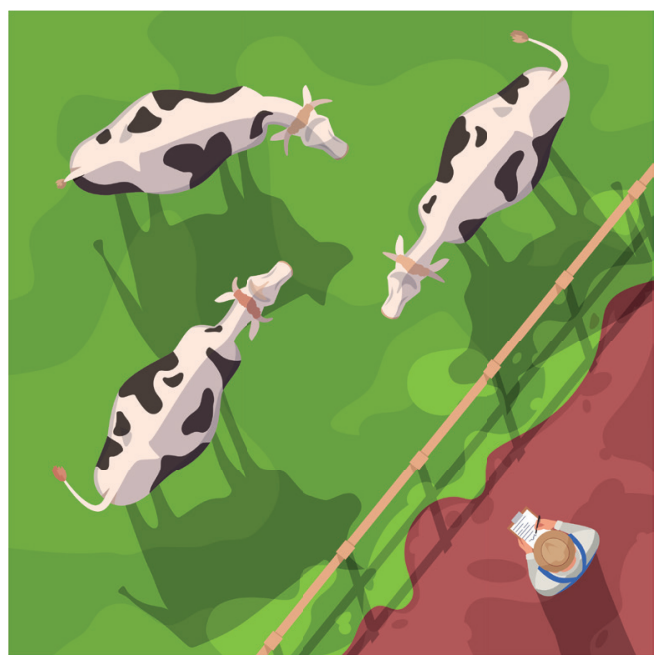

\section{Los reyes del mundo}

Como les hemos mostrado en estos últimos párrafos, los humanos no somos los dominantes planetarios en términos de biomasa. Bajo cualquier indicador ecológico de dominancia, las vacas son los grandes ganadores cuando se trata de una sola especie y las plantas, cuando hablamos de todo un reino. Esto no quiere decir que deberíamos de "engordar" como humanidad para ganar la competencia y mucho menos significa que debemos eliminar a todos los demás competidores, jaunque le estamos echando ganas!

Esta dominancia es el resultado de una estructura ecológica básica global. En primer lugar, necesitamos a las plantas -y las algas-, porque son las productoras de biomasa de nuestro planeta, al llevar a cabo la fotosíntesis. Gracias a ellas todos los demás organismos pueden crecer y existir. Sin plantas, no habría biomasa para nadie más.

Pero la vida no se trata sólo de acumular masa, también necesitamos recircular los nutrientes, a través de la descomposición para seguir creciendo. Para eso tenemos ese enorme número de microorganismos, encargados de mantener el equilibrio planetario, al degradar los restos vegetales y animales, permitiendo que la materia se reintegre al sistema. Los microorganismos son los grandes recicladores que hacen posible la permanencia de la vida en nuestro planeta.

Finalmente, somos muchas - muchísimas - personas en este planeta y necesitamos alimentarnos todos. Dada nuestra evolución, tenemos una tendencia natural a que nos encante la carne y, mientras la dieta dominante siga siendo carnívora, seguiremos teniendo miles de millones de vacas para satisfacer esta demanda. Sólo en esta parte podemos esperar un cambio en la dominancia, si decidiéramos, como humanidad, reducir nuestro enorme consumo de carne. Mientras tanto, seguiremos "pesando" menos que nuestros primos rumiantes.

Así que cada uno de los pedazos de esta historia, de estos rounds, estaba destinado a perderse. No hay manera de que exista un equilibrio global. Si la biomasa humana fuera mayor a la de las plantas o los microorganismos no habría forma de mantener esta dieta carnívora, si no es con muchísimas reses. 
Esta teoría se conoce como la pirámide ecológica, y fue propuesta por primera vez en 1942 por Evelyn Hutchinson y Raymond Lindeman, pero sólo gracias a la tecnología actual, al fin se ha podido demostrar con estimaciones planetarias.

Como nota final, queremos recalcar que, aunque no dominemos en términos de biomasa, no debemos olvidarnos de los profundos impactos de nuestra humanidad en el mundo. Somos los principales causantes de un calentamiento excesivo y acelerado, de la modificación en la composición química de las capas de fluidos globales —océanos y atmósfera-, de la contaminación masiva de ecosistemas terrestres, de la pérdida de biodiversidad, el cambio en la cubierta vegetal..., por mencionar algunos. Nuestros impactos son muchos y profundos. Ninguna especie en toda la historia había logrado mover la cantidad de materia y energía como nosotros; o modificar el paisaje global de manera tan profunda. Contemplado desde cualquier otro punto de vista — que no sea solamente la biomasa-, realmente somos los reyes del mundo, aunque hasta ahora mantenemos un reinado tiránico.

\section{Referencias}

* Bar-On, Y. M., Phillips, R. y Milo, R. (2018). The biomass distribution on Earth. Proceedings of the National Academy of Sciences, 115(25), 6506-6511. Dol: https://doi.org/10.1073/pnas.1711842115

Crowther, T. W., Glick, H. B., Covey, K. R., Bettigole, C., Maynard, D. S., Thomas, S. M., Smith, J. R., Hintler, G., Duguid, M. C., Amatulli, G., Tuanmu, M. N., Jetz, W., Salas, C., Stam, C., Piotto, D., Tavani, R., Green, S., Bruce, G., Williams, S. J., ... Bradford M. A. (2015. 10 de septiembre). Mapping tree density at a global scale. Nature, 525(7568), 201-205. Dol: https://www.doi.org/10.1038/nature14967

* Flemming, H. C., y Wuertz, S. (2019). Bacteria and archaea on Earth and their abundance in biofilms. Nature Reviews Microbiology, 17(4), 247-260. Dol: https:// www.doi.org/10.1038/s41579-019-0158-9

* Fao stats. (s. f.). Consultado el 15 de febrero de 2020. http://www.fao.org/faostat/ es/

\section{Cómo CITAR ESTE ARTículo}

* Murray-Tortarolo, Guillermo N. y Murguía-Flores, Fabiola. (2020, noviembrediciembre). Una competencia de pesos pesados por el dominio del mundo. Revista Digital Universitaria (RDU), 21(6). Dol: http://doi.org/10.22201/ cuaieed.16076079e.2020.21.6.15 